Article

\title{
Long-Term Follow-Up of 12 Patients Treated with Bilateral Pallidal Stimulation for Tardive Dystonia
}

\author{
Hiroshi Koyama ${ }^{1}$, Hideo Mure ${ }^{1,2, *}$, Ryoma Morigaki ${ }^{1,3,4} \oplus$, Ryosuke Miyamoto ${ }^{3,5}$, Kazuhisa Miyake ${ }^{1}$, \\ Taku Matsuda ${ }^{1}$, Koji Fujita ${ }^{3,5}$, Yuishin Izumi ${ }^{3,5}$, Ryuji Kaji ${ }^{5,6}$, Satoshi Goto ${ }^{3,7}$ and Yasushi Takagi ${ }^{1}$ \\ 1 Department of Neurosurgery, Graduate School of Biomedical Sciences, Tokushima University, \\ Tokushima 770-8503, Japan; koyama.hiroshi.jf@mail.hosp.go.jp (H.K.); \\ morigaki.riyoma.1@tokushima-u.ac.jp (R.M.); med.miyake@tokushima-u.ac.jp (K.M.); \\ matsuda.taku@tokushima-u.ac.jp (T.M.); ytakagi@tokushima-u.ac.jp (Y.T.) \\ 2 Center for Neuromodulation, Department of Neurosurgery, Kurashiki Heisei Hospital, \\ Kurashiki 710-0826, Japan \\ 3 Parkinson's Disease and Dystonia Research Center, Tokushima University Hospital, \\ Tokushima 770-8503, Japan; ryom@tokushima-u.ac.jp (R.M.); kfujita@tokushima-u.ac.jp (K.F.); \\ yizumi@tokushima-u.ac.jp (Y.I.); sgoto@tokushima-u.ac.jp (S.G.) \\ 4 Department of Advanced Brain Research, Graduate School of Biomedical Sciences, Tokushima University, \\ Tokushima 770-8503, Japan \\ 5 Department of Neurology, Graduate School of Biomedical Sciences, Tokushima University, \\ Tokushima 770-8503, Japan; rkaji@tokushima-u.ac.jp \\ 6 National Hospital Organization Utano Hospital, Kyoto 616-8255, Japan \\ 7 Department of Neurodegenerative Disorders Research, Graduate School of Biomedical Sciences, \\ Tokushima University, Tokushima 770-8503, Japan \\ check for \\ * Correspondence: c000030424@tokushima-u.ac.jp; Tel.: +81-86-427-1111
} updates

Citation: Koyama, H.; Mure, H.; Morigaki, R.; Miyamoto, R.; Miyake, K.; Matsuda, T.; Fujita, K.; Izumi, Y.; Kaji, R.; Goto, S.; et al. Long-Term Follow-Up of 12 Patients Treated with Bilateral Pallidal Stimulation for Tardive Dystonia. Life 2021, 11, 477. https://doi.org/10.3390/life11060477

Academic Editor: Alfredo Conti

Received: 22 April 2021

Accepted: 20 May 2021

Published: 24 May 2021

Publisher's Note: MDPI stays neutral with regard to jurisdictional claims in published maps and institutional affiliations.

Copyright: (C) 2021 by the authors. Licensee MDPI, Basel, Switzerland. This article is an open access article distributed under the terms and conditions of the Creative Commons Attribution (CC BY) license (https:// creativecommons.org/licenses/by/ $4.0 /)$.

\begin{abstract}
Tardive dystonia (TD) is a side effect of prolonged dopamine receptor antagonist intake. TD can be a chronic disabling movement disorder despite medical treatment. We previously demonstrated successful outcomes in six patients with TD using deep brain stimulation (DBS); however, more patients are needed to better understand the efficacy of DBS for treating TD. We assessed the outcomes of 12 patients with TD who underwent globus pallidus internus (GPi) DBS by extending the follow-up period of previously reported patients and enrolling six additional patients. All patients were refractory to pharmacotherapy and were referred for surgical intervention by movement disorder neurologists. In all patients, DBS electrodes were implanted bilaterally within the GPi under general anesthesia. The mean ages at TD onset and surgery were $39.2 \pm 12.3$ years and $44.6 \pm 12.3$ years, respectively. The Burke-Fahn-Marsden Dystonia Rating Scale (BFMDRS) performed the preoperative and postoperative evaluations. The average BFMDRS improvement rate at 1 month postoperatively was $75.6 \pm 27.6 \%(p<0.001)$. Ten patients were assessed in the long term $(78.0 \pm 50.4$ months after surgery), and the long-term BFMDRS improvement was $78.0 \pm 20.4 \%$. Two patients responded poorly to DBS. Both had a longer duration from TD onset to surgery and older age at surgery. A cognitive and psychiatric decline was observed in the oldest patients, while no such decline ware observed in the younger patients. In most patients with TD, GPi-DBS could be a beneficial therapeutic option for long-term relief of TD.
\end{abstract}

Keywords: tardive dystonia; deep brain stimulation; globus pallidus internus; long-term follow-up

\section{Introduction}

Long-term treatment with dopamine receptor antagonists may have adverse consequences, such as the development of tardive syndrome (TDS), which includes tardive dyskinesia and tardive dystonia (TD) [1-4]. Both tardive movement disorders cause emotional and social distress; TD has a faster onset and is more painful, distressing, and disabling than tardive dyskinesia [2]. Clinical presentations of TD are usually similar to those of focal, 
segmental, or generalized primary dystonia. Cervical muscles are affected in two-thirds of all patients with TD [5,6]. Treatment of TD involves gradual withdrawal of TD-inducing medications, the substitution of atypical neuroleptics (e.g., clozapine) or the administration of tetrabenazine, dopamine agonists, and anticholinergics [4,7]. Pharmacological treatment of TD may be challenging and ineffective. Globus pallidus internus (GPi) deep brain stimulation (DBS) has been proven to be effective in medically refractory cases of primary generalized, segmental, or focal dystonia [8-11]. On reviewing the therapeutic perspective on TDS [3], we found that clinical similarity between TD and primary dystonia has led to the development of neurosurgical treatment modalities such GPi-DBS [8,12,13]. In 2008, we reported that GPi-DBS improved the dystonia motor score by $86 \%$ in six patients with TD at a median follow-up of 21 months [14]. To confirm the long-term efficacy and safety of GPi-DBS in patients with severe TD, we extended the follow-up of these six patients and studied six more patients. We assessed the clinical outcomes of GPi-DBS in a total of 12 patients with severe TD, 10 of whom were followed up for longer than 2 years (2-15 years) after surgery.

\section{Materials and Methods}

All patients included in this study fulfilled the diagnostic criteria for TD proposed by Adityanjee et al. [2]. To confirm that all inclusion criteria were fulfilled, the history and clinical characteristics of each patient were reviewed at the movement disorder team meetings consisting of at least one neurologist, one psychiatrist, and two neurosurgeons. We retrospectively retrieved the medical records of all patients with TD who received GPi-DBS at our hospital between January 2004 and December 2019. All patients included in this study provided written informed consent for the DBS surgery and follow-up examinations. This study was approved by the local ethical committee at Tokushima University. Bilateral GPi-DBS was performed as reported previously [14,15]. Under general anesthesia with propofol or desflurane, microelectrode recordings were performed for all patients. Quadripolar electrodes (model 3387, Medtronic, MN or $1.5 \mathrm{~mm}$ space, St. Jude Medical, $\mathrm{MN}$ ) were implanted into the ventral margin of the GPi and connected to programmable pulse generators (Activa SC, Medtronic or Infinity, St. Jude Medical) implanted subcutaneously on the same day. Intraoperative microelectrode recordings and postoperative computed tomography confirmed appropriate electrode positioning. The electrode and electrical parameters providing the best improvement of dystonic symptoms with the least adverse effects were determined at three to four weeks after surgery. Neurological examination with the Burke-Fahn-Marsden Dystonia Rating Scale (BFMDRS) was performed preoperatively and postoperatively by the same rating investigator from the movement disorder team. To evaluate changes in BFMDRS from before surgery to 1 month and last follow-up period, statistical analyses were performed using the paired $t$-test. $p$ values less than 0.05 were considered statistically significant.

\section{Results}

Twelve patients (seven men and five women) with severe TD were included in this study. Their characteristics are shown in Tables 1 and 2. Although the data of six patients (patient number 1-6) have been previously reported, their data were updated by extending the follow-up period. Six additional patients (patient number 7-12) were enrolled. The mean age at the time of surgery of all patients was $44.6 \pm 12.5$ years. The mean neuroleptic exposure was $9.1 \pm 8.6$ years, and the mean age at TD onset was $39.2 \pm 12.3$ years. The mean duration between TD onset and surgery was $4.5 \pm 4.2$ years. Depression, schizophrenia, panic disorder, and bipolar disorder were underlying comorbidities, for which medications such as etizolam, sulpiride, and haloperidol were commonly prescribed. In 11 patients, TD affected the neck. The mouth and upper and lower extremities were affected in five patients. In all patients, optimal results were obtained with the following stimulator settings: mean amplitude of $2.8 \pm 0.9 \mathrm{~V} / 4.0 \pm 0.4 \mathrm{~mA}$ (range, 1.7-4.4 V/ 3.5-4.2 mA), mean frequency of $94.5 \pm 35.0 \mathrm{~Hz}$ (range, 60-130 Hz), and pulse width of $348.2 \pm 163.0 \mu \mathrm{s}$ (range, 60-450 $\mu \mathrm{s}$ ) (see Table 2). 
Table 1. Patient characteristics.

\begin{tabular}{|c|c|c|c|c|c|c|c|c|}
\hline Patient Number & Age at Surgery & Gender & Age at TD Onset & $\begin{array}{c}\text { Underlying } \\
\text { Psychiatric Disease } \\
\text { and Onset Age }\end{array}$ & Suspected Drugs & $\begin{array}{c}\text { Drug Exposure } \\
\text { (Years) }\end{array}$ & $\begin{array}{c}\text { Duration Between } \\
\text { TD Onset and DBS } \\
\text { (Years) }\end{array}$ & $\begin{array}{l}\text { Region on } \\
\text { Dystonia }\end{array}$ \\
\hline 1 & 48 & $\mathrm{~F}$ & 46 & Depression, 40 & Sulpiride & 2 & 2 & Eye, mouth, neck. \\
\hline 2 & 48 & $\mathrm{~F}$ & 47 & Bipolar disorder, 40 & Tiapride & 6 & 1 & $\begin{array}{l}\text { Neck, bilateral } \\
\text { arms, left leg. }\end{array}$ \\
\hline 3 & 30 & M & 29 & Schizophrenia, 28 & Risperidone & 1 & 0.5 & $\begin{array}{l}\text { Left arm, trunk, } \\
\text { right leg. }\end{array}$ \\
\hline 4 & 47 & $\mathrm{~F}$ & 40 & Panic disorder, 31 & Perphenazine & 5 & 7 & Neck, trunk. \\
\hline 5 & 39 & M & 39 & Depression, 36 & Perphenazine & 0.5 & 0.5 & $\begin{array}{l}\text { Neck, right arm, } \\
\text { right leg. }\end{array}$ \\
\hline 6 & 55 & M & NA & Anxiety neurosis, 51 & Haloperidol & 4 & & NA \\
\hline 7 & 42 & M & 41 & Depression, 33 & Sulpiride & 7 & 1 & $\begin{array}{l}\text { Neck, mouth, } \\
\text { bilateral arms. }\end{array}$ \\
\hline 8 & 30 & $\mathrm{~F}$ & 19 & Schizophrenia, 15 & $\begin{array}{l}\text { Risperidone } \\
\text { Haloperidol }\end{array}$ & 14 & 11 & $\begin{array}{l}\text { Eye, mouth, neck, } \\
\text { bilateral legs. }\end{array}$ \\
\hline 10 & 69 & M & 59 & Bipolar disorder, 37 & $\begin{array}{l}\text { Aripiprazole } \\
\text { Quetiapine }\end{array}$ & 32 & 10 & Neck, trunk \\
\hline 11 & 55 & $\mathrm{~F}$ & 44 & Schizophrenia, 43 & $\begin{array}{l}\text { Risperidone } \\
\text { Haloperidol }\end{array}$ & 10 & 9 & $\begin{array}{c}\text { Eye, mouth, neck, } \\
\text { trunk }\end{array}$ \\
\hline 12 & 49 & M & 48 & Schizophrenia, 31 & Risperidone & 17 & 1 & $\begin{array}{l}\text { Neck, mouth, } \\
\text { bilateral arms. }\end{array}$ \\
\hline
\end{tabular}


Table 2. The outcomes at baseline, 1 month and long-follow up after GPi-DBS.

\begin{tabular}{|c|c|c|c|c|c|c|c|}
\hline Patient Number & BFMDRS Baseline & $\begin{array}{l}\text { BFMDRS } 1 \text { Month } \\
\text { after DBS }\end{array}$ & $\begin{array}{l}\text { Improvement Rate } \\
\text { at } 1 \text { Month (\%) }\end{array}$ & $\begin{array}{l}\text { BFMDRS at Last } \\
\text { Follow-Up }\end{array}$ & $\begin{array}{l}\text { Improvement Rate } \\
\text { at Last Follow-Up } \\
(\%)\end{array}$ & $\begin{array}{l}\text { Postoperative } \\
\text { Follow-Up Time } \\
\text { (Months) }\end{array}$ & $\begin{array}{c}\text { Stimulation Parameters with } \\
\text { Best Response } \\
\text { Amplitude/Frequency } \\
(\mathrm{Hz}) / \text { Pulse width }(\mu \mathrm{s})\end{array}$ \\
\hline 2 & 21 & 8 & 61.9 & 2 & 90.5 & 88 & $\begin{array}{l}\text { Rt. Case }(+) 1(-) 2.0 \mathrm{~V} / 130 / 450 \\
\text { Lt. Case }(+) 2(-) 2.5 \mathrm{~V} / 130 / 450\end{array}$ \\
\hline 3 & 19 & 4 & 78.9 & 2 & 89.5 & 107 & $\begin{array}{l}\text { Rt. Case }(+) 2(-) 2.8 \mathrm{~V} / 130 / 450 \\
\text { Lt. Case }(+) 2(-) 2.5 \mathrm{~V} / 130 / 450\end{array}$ \\
\hline 4 & 32 & 0 & 100.0 & 4 & 87.5 & 186 & $\begin{array}{c}\text { Rt. Case }(+) 0(-) 1(-) 2(-) \\
1.6 \mathrm{~V} / 130 / 450 \\
\text { Lt. Case }(+) 1(-) 2(-) \\
1.8 \mathrm{~V} / 130 / 450\end{array}$ \\
\hline 5 & 12 & 1 & 91.7 & 3.5 & 70.8 & 127 & $\begin{array}{c}\text { Bilateral Case }(+) 1(-) \\
2.0 \mathrm{~V} / 130 / 60\end{array}$ \\
\hline 6 & 75 & 9 & 88.0 & 9 & 88.0 & 3 & NA \\
\hline 8 & 26 & 1 & 96.2 & 3 & 88.5 & 24 & $\begin{array}{c}\text { Bilateral Case }(+) 2(-) 4.2 \\
\mathrm{~mA} / 130 / 60\end{array}$ \\
\hline 9 & 29.5 & 1 & 96.6 & 1 & 96.6 & 56 & $\begin{array}{l}\text { Rt. Case }(+) 1(-) 3.5 \mathrm{~V} / 60 / 450 \\
\text { Lt. Case }(+) 1(-) 3.8 \mathrm{~V} / 60 / 450\end{array}$ \\
\hline 10 & 51 & 45 & 11.8 & 45 & 11.8 & 6 & $\begin{array}{c}\text { Bilateral Case }(+) 1(-) 3.5 \\
\mathrm{~mA} / 60 / 450\end{array}$ \\
\hline 11 & 74 & 26 & 64.9 & 55 & 25.7 & 46 & $\begin{array}{c}\text { Bilateral Case }(+) 1(-) 2(-) \\
3.0 / 60 / 180\end{array}$ \\
\hline 12 & 23 & 3 & 87.0 & 3 & 87.0 & 24 & $\begin{array}{c}\text { Rt. Case }(+) 1(-) 2(-) 4.1 \\
\mathrm{~mA} / 90 / 400 \\
\text { Lt. Case }(+) 2(-) 4.4 \mathrm{~mA} / 90 / 450\end{array}$ \\
\hline
\end{tabular}


The mean preoperative BFMDRS score was $35.3 \pm 20.7(n=12$, range, 12-75). All patients had improvement in BFMDRS scores postoperatively (Figure 1); the mean BFMDRS score was $9.7 \pm 14.6$ ( $\mathrm{n}=11, p<0.001$, paired $t$-test), and the mean improvement rate was $77.8 \%$ (range, $12 \%-100 \%$ ) at 1 month after surgery. At the last follow-up $(65.7 \pm 54.1$ months), the improvement was maintained with a $75 \%(n=12,12 \%-97 \%$, $p<0.001$ ) decrease for the total BFMDRS score (Supplementary Figure S1). Individual changes in the BFMDRS score from baseline to 1 month and the last follow-up are shown in Supplementary Figure S1. Ten patients were followed up for longer than 2 years (mean follow-up, $78 \pm 50.4$ months after surgery); the BFMDRS score was $8.9 \pm 17.3$ ( $\mathrm{n}=10$, $p<0.0001$, paired $t$-test), and the mean improvement rate was maintained in $80.4 \pm 20.4 \%$ of them.

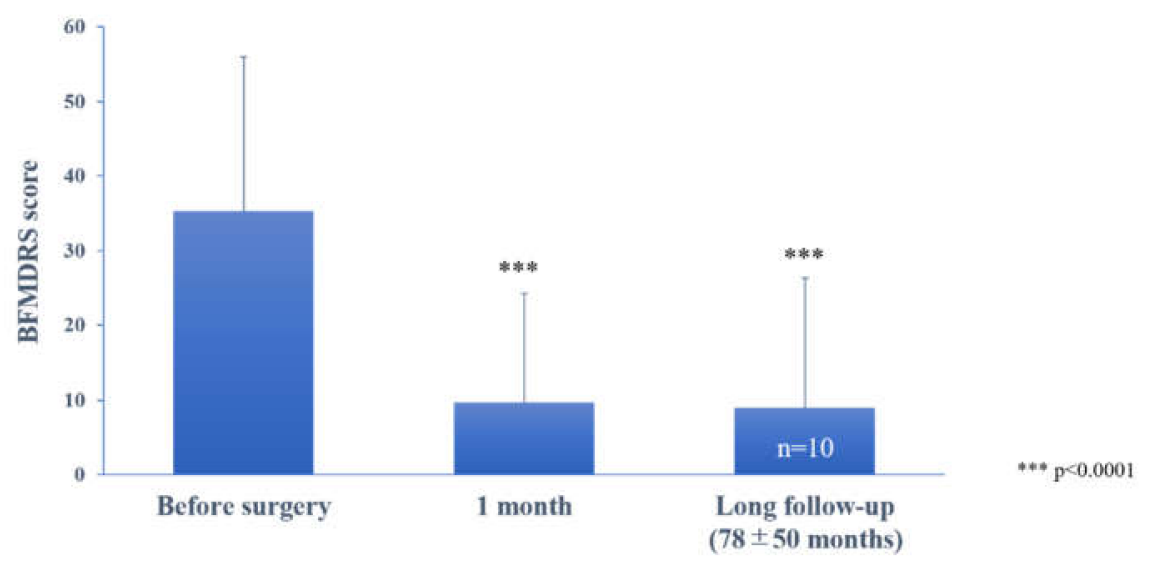

Figure 1. The effect of bilateral pallidal stimulation on tardive dystonia at 1 month postoperatively and at long-term postoperative follow-up (78 \pm 50 months). Motor symptoms were assessed using the Burke-Fahn-Marsden Dystonia Rating Scale (BFMDRS). Vertical bars represent the standard error of the mean. ${ }^{* * *} p<0.0001$, paired $t$-test, compared with the preoperative score.

Preoperative and postoperative clinical features of a representative patient (patient number 9) are shown in the Supplementary videos. Adverse events of DBS surgery included postoperative wound infection and worsening mania, which improved with antibiotic therapy and adjustment of DBS parameters, respectively (Table 2). In two patients (patient number 10 and 11), GPi-DBS did not lead to sufficient beneficial effects. One patient (patient number 10) responded poorly to the stimulation and experienced worsened mania 1 month postoperatively. Another patient (patient number 11) had a BFMDRS score improvement of $65 \%$ at 1 month postoperatively; however, the efficacy of DBS gradually reduced, and the improvement was $25 \%$ at 46 months postoperatively. Both these patients had an older age at surgery ( 69 and 55 years old) and a longer duration between TD onset and surgery (19 and 9 years).

\section{Discussion}

We enrolled 12 patients with severe TD who underwent GPi-DBS at our hospital. Significant improvement in mean motor score was observed at both short- $(75.6 \%)$ and long-term follow-up (>2 years, 78.0\%) after GPi-DBS. Since 1980, 117 cases of TDS treated with DBS have been reported in 35 studies, many of which were single case reports. The 10 patients reported by Damier et al. in their case series exhibited a mean improvement of $55 \% \pm 15.5 \%$ in the Abnormal Involuntary Movement Scale (AIMS) score at 6 months postoperatively [16]. A phase II study reported improvement of more than $60 \%$ in both the AIMS and Extrapyramidal Symptoms Rating Scale scores for more than 6 years postoperatively and provided level C evidence of the American Academy of Neurology guidelines for the positive effects of GPi-DBS in patients with TDS. Our study included a larger number of patients than previous case series studies; this could contribute to the existing evidence on the beneficial effect of GPi-DBS on TD. In the present study, however, the BFMDRS 
score improvement rate in patient 10 was poor, and patient 11 had improved 1 month postoperatively but gradually worsened in the long term. Both had developed a mental illness after the age of 35, and patient 5 had been receiving antipsychotic drugs for over 30 years; these may be poor prognostic factors. Andrews et al. reported that, for all types of dystonia, shorter durations from onset to surgery were associated with better surgical outcomes [17]. However, according to the criteria proposed by the French Stimulation for Tardive Dyskinesia, DBS should only be considered in patients with persistent $(>1$ year) and severely disabling TDS treated with clozapine or tetrabenazine for at least 4 weeks. Our results emphasize the importance of considering surgical treatment for disabling TD refractory to medical treatment early in the disease course.

In this study, the optimal DBS parameters in four patients were long pulse width $(180-450 \mu \mathrm{s})$ and low frequency $(60 \mathrm{~Hz})$. These stimulation parameters may be effective in patients with dystonia. However, the use of high- vs. low-frequency stimulation in dystonia has shown mixed results. While Alterman et al. suggested that the use of $60 \mathrm{~Hz}$ stimulation can be beneficial in some patients [18], another group preferred highfrequency stimulation [19]. Moro et al. concluded that high-amplitude and high-frequency stimulation might lead to better outcomes in patients with cervical dystonia [20]. Various pulse widths have been recommended for GPi-DBS. Coubes et al. recommended the use of $450 \mu \mathrm{s}$ [21]. Another study did not show any significant difference between pulse widths of 60,120 , and $450 \mu \mathrm{s}$ [22]. At present, because of these conflicting results, the stimulation parameters used during DBS depend to a large extent on personal experience.

This report supports the effectiveness of GPi-DBS for treating severe TD refractory to best medical treatment. However, older age at the time of surgery and longer duration between TD onset and surgery might be poor prognostic factors for GPi-DBS.

Supplementary Materials: The following are available online at https://www.mdpi.com/article/ 10.3390/life11060477/s1, Video S1: The patient (case 9) shows cervical, truncal, and left-sided lower extremity dystonia., Video S2: Five years after bilateral globus pallidus internus deep brain stimulation, the patient shows marked improvement in his dystonic symptoms.

Author Contributions: The conception or design of the work: H.M. and H.K. The acquisition, analysis, or interpretation of data for the work: H.M., R.M. (Ryoma Morigaki), K.M., R.M. (Ryosuke Miyamoto), and T.M. Drafting the work: H.K. and H.M. Revising the work critically for important intellectual content: R.M. (Ryoma Morigaki), K.F., Y.I., R.K., Y.T. and S.G. Final approval of the version to be published and agreement to be accountable for all aspects of the work in ensuring that questions related to the accuracy or integrity of any part of the work are appropriately investigated and resolved: H.M., R.M. (Ryoma Morigaki), Y.I., R.K., Y.T. and S.G. All authors have read and agreed to the published version of the manuscript.

Funding: This work was supported in part by grants from the Ministry of Education, Culture, Sports, Science and Technology of Japan (grants-in-aid for Scientific Research no. 16K10788, 16KK0182, 17K10899, and 20K17932). The Department of Advanced Brain Research is supported by Beauty Life Corporation.

Institutional Review Board Statement: The study was conducted according to the guidelines of the Declaration of Helsinki and approved by the Institutional Ethics Committee of Tokushima University (approval number 3743, date of approval 22 June 2020).

Informed Consent Statement: Informed consent was obtained from all patients involved in the study. Written informed consent has been obtained from the patients to publish this paper.

Data Availability Statement: The data presented in this study are available on request from the corresponding author. The data are not publicly available due to patient privacy considerations.

Acknowledgments: Department of Advanced Brain Research is supported by Beauty Life Corporation.

Conflicts of Interest: The authors declare no conflict of interest. The funders had no role in the design of the study; in the collection, analyses, or interpretation of data; in the writing of the manuscript, or in the decision to publish the results. 


\section{References}

1. Burke, R.E.; Fahn, S.; Jankovic, J.; Marsden, C.D.; Lang, A.E.; Gollomp, S.; Ilson, J. Tardive dystonia: Late-onset and persistent dystonia caused by antipsychotic drugs. Neurology 1982, 32, 1335. [CrossRef] [PubMed]

2. Aderibigbe, Y.A.; Jampala, V.C.; Mathews, T. The current status of tardive dystonia. Biol. Psychiatry 1999, 45, 715-730.

3. Morigaki, R.; Mure, H.; Kaji, R.; Nagahiro, S.; Goto, S. Therapeutic Perspective on Tardive Syndrome with Special Reference to Deep Brain Stimulation. Front. Psychiatry 2016, 7, 207. [CrossRef] [PubMed]

4. Lerner, P.P.; Miodownik, C.; Lerner, V. Tardive dyskinesia (syndrome): Current concept and modern approaches to its management. Psychiatry Clin. Neurosci. 2015, 69, 321-334. [CrossRef]

5. Franzini, A.; Marras, C.; Ferroli, P.; Zorzi, G.; Bugiani, O.; Romito, L.; Broggi, G. Long-term high-frequency bilateral pallidal stimulation for neuroleptic-induced tardive dystonia. J. Neurosurg. 2005, 102, 721-725. [CrossRef]

6. Kiriakakis, V.; Bhatia, K.P.; Quinn, N.P.; Marsden, C.D. The natural history of tardive dystonia. A long-term follow-up study of 107 cases. Brain 1998, 121, 2053-2066. [CrossRef]

7. Lerner, V.; Miodownik, C. Motor Symptoms of Schizophrenia: Is Tardive Dyskinesia a Symptom or Side Effect? A Modern Treatment. Curr. Psychiatry Rep. 2011, 13, 295-304. [CrossRef] [PubMed]

8. Ostrem, J.L.; Starr, P.A. Treatment of dystonia with deep brain stimulation. Neurotherapeutics 2008, 5, 320-330. [CrossRef] [PubMed]

9. Starr, P.A.; Turner, R.S.; Rau, G.; Lindsey, N.; Heath, S.; Volz, M.; Ostrem, J.L.; Marks, W.J. Microelectrode-guided implantation of deep brain stimulators into the globus pallidus internus for dystonia: Techniques, electrode locations, and outcomes. J. Neurosurg. 2006, 104, 488-501. [CrossRef] [PubMed]

10. Vidailhet, M.; Vercueil, L.; Houeto, J.-L.; Krystkowiak, P.; Benabid, A.-L.; Cornu, P.; Lagrange, C.; Du Montcel, S.T.; Dormont, D.; Grand, S.; et al. Bilateral Deep-Brain Stimulation of the Globus Pallidus in Primary Generalized Dystonia. N. Engl. J. Med. 2005, 352, 459-467. [CrossRef]

11. Kupsch, A.; Benecke, R.; Müller, J.; Trottenberg, T.; Schneider, G.-H.; Poewe, W.; Eisner, W.; Wolters, A.; Müller, J.-U.; Deuschl, G.; et al. Pallidal Deep-Brain Stimulation in Primary Generalized or Segmental Dystonia. N Engl. J. Med. 2006, 355, 1978-1990. [CrossRef] [PubMed]

12. Kefalopoulou, Z.; Paschali, A.; Markaki, E.; Vassilakos, P.; Ellul, J.; Constantoyannis, C. A double-blind study on a patient with tardive dyskinesia treated with pallidal deep brain stimulation. Acta Neurol. Scand. 2009, 119, 269-273. [CrossRef]

13. Magariños-Ascone, C.; Regidor, I.; Gómez-Galán, M.; Cabañes-Martínez, L.; Figueiras-Méndez, R. Deep brain stimulation in the globus pallidus to treat dystonia: Electrophysiological characteristics and 2 years' follow-up in 10 patients. Neuroscience 2008, 152, 558-571. [CrossRef]

14. Sako, W.; Goto, S.; Shimazu, H.; Murase, N.; Matsuzaki, K.; Tamura, T.; Mure, H.; Tomogane, Y.; Arita, N.; Yoshikawa, H.; et al. Bilateral deep brain stimulation of the globus pallidus internus in tardive dystonia. Mov. Disord. 2008, 23, 1929-1931. [CrossRef] [PubMed]

15. Sako, W.; Morigaki, R.; Mizobuchi, Y.; Tsuzuki, T.; Ima, H.; Ushio, Y.; Nagahiro, S.; Kaji, R.; Goto, S. Bilateral pallidal deep brain stimulation in primary Meige syndrome. Park. Relat. Disord. 2011, 17, 123-125. [CrossRef] [PubMed]

16. Damier, P.; Thobois, S.; Witjas, T.; Cuny, E.; Derost, P.; Raoul, S.; Mertens, P.; Peragut, J.-C.; Lemaire, J.-J.; Burbaud, P.; et al. Bilateral Deep Brain Stimulation of the Globus Pallidus to Treat Tardive Dyskinesia. Arch. Gen. Psychiatry 2007, 64, 170-176. [CrossRef]

17. Andrews, C.; Aviles-Olmos, I.; Hariz, M.; Foltynie, T. Which patients with dystonia benefit from deep brain stimulation? A metaregression of individual patient outcomes. J. Neurol. Neurosurg. Psychiatry 2010, 81, 1383-1389. [CrossRef]

18. Alterman, R.L.; Miravite, J.; Weisz, D.; Shils, J.L.; Bressman, S.B.; Tagliati, M. Sixty hertz pallidal deep brain stimulation for primary torsion dystonia. Neurology 2007, 69, 681-688. [CrossRef]

19. Kupsch, A.; Klaffke, S.; Meissner, W.; Arnold, G.; Schneider, G.H.; Maier-Hauff, K.; Trottenberg, T. The effects of frequency in pallidal deep brain stimulation for primary dystonia. J. Neurol. 2003, 250, 1201-1205. [CrossRef]

20. Moro, E.; Piboolnurak, P.; Arenovich, T.; Hung, S.W.; Poon, Y.-Y.; Lozano, A.M. Pallidal stimulation in cervical dystonia: Clinical implications of acute changes in stimulation parameters. Eur. J. Neurol. 2009, 16, 506-512. [CrossRef]

21. Coubes, P.; Cif, L.; El Fertit, H.; Hemm, S.; Vayssiere, N.; Serrat, S.; Picot, M.C.; Tuffery, S.; Claustres, M.; Echenne, B.; et al. Electrical stimulation of the globus pallidus internus in patients with primary generalized dystonia: Long-term results. $J$. Neurosurg. 2004, 101, 189-194. [CrossRef] [PubMed]

22. Vercueil, L.; Houeto, J.L.; Krystkowiak, P.; Lagrange, C.; Cassim, F.; Benazzouz, A.; Pidoux, B.; Destée, A.; Agid, Y.; Cornu, P.; et al. Effects of pulse width variations in pallidal stimulation for primary generalized dystonia. J. Neurol. 2007, 254, 1533-1537. [CrossRef] [PubMed] 